\title{
Pancreatic Ductal Adenocarcinoma: Implications of Epigenetic Role Related the Src Pathway
}

\section{Padin-Iruegas $\mathrm{ME}^{1 *, \#}$, Eugenyeva $\mathrm{E}^{3 *, \#}$, Herranz-Carnero $\mathrm{M}^{4}$, Aguín Losada $\mathrm{S}^{2}$, Brozos Vázquez $\mathrm{E}^{2}$, Abdullkader $\mathrm{I}^{5}$, Antúnez $\mathrm{JR}^{5}$, Ruibal- Morell $A^{4}$ and López-López $\mathbf{R}^{2}$}

nctional Biology and Health Sciences Department, University of Vigo, Spain

${ }^{2}$ Medical Oncology Department, Hospital Clínico, Santiago de Compostela, Spain

${ }^{3}$ Pathology Department, Hospital Central Denia, Alicante, Spain

${ }^{4}$ Nuclear Medicine Department, Hospital Clínico, Santiago de Compostela, Spain

${ }^{5}$ Pathology Department, Hospital Clínico, Santiago de Compostela, Spain

\#Both authors contribute equally to this work

\begin{abstract}
Epigenetic has become, in recent years, in a very important process in the control of several pathologies, including cancer. DNA methylation has been described in numerous studies as crucial for differentiation control, cell proliferation and invasion in cancer.

Pancreas ductal adenocarcinoma is one of the most deadly diseases of our society; its complexity and variability have become one of the medical challenges of this decade. Combining the potential of epigenetic with the high mortality and the limited knowledge of pancreatic ductal adenocarcinoma origin, may result in new approaches for diagnosis, treatment and monitoring, crucial in this pathology.

For this purpose, we analyzed genes involved in different cellular processes (GSTP1, p16, RASFF1A, RARß2, CyclinD2, HIN-1, SOCS1, TIMP3, DAPK and TWIST1) in 61 cases of pancreatic ductal adenocarcinoma. A first approach led us to analyze the Src pathway, never studied in this sense, as crucial in the development of this pathology. Clusters for clinicopathological characteristics and epigenetic profiles were obtained.

The high degree of methylation of these adenocarcinomas, and the statistical relationship between Src pathway methylation and clinicopathological profile, has been postulated, for the first time. These results show the importance of this pathway in pancreatic disease, opening a new challenge for research and therapy.
\end{abstract}

Keywords: Epigenetic; Src pathway; Tumorogenesis; Pancreatic cancer

\section{Introduction}

Cancer is a complex disease characterized by multiple genetic and epigenetic genomic alterations [1,2]. DNA methylation is one of the most important epigenetic modifications, and plays a critical functional role in development, differentiation and progression [2]. Accumulating evidence demonstrates that cancer is associated with aberrant DNA methylation [2]. Promoter regions are usually enriched with $\mathrm{CpG}$ dinucleotides, known as $\mathrm{CpG}$ islands; hypermethylation of these islands correlates with transcriptional silencing of tumor suppressor genes.

DNA methylation of $\mathrm{CpG}$ islands located in the promoter regions of tumor-related genes, such as p14, p15, p16, p73, APC, hMLH1, BRCA1, MGMT, GSTP1, CDH1, TIMP3 and DAPK-1, is associated with silencing of such genes [1]. Conversely, increased expressions of oncogenes were associated with hypomethylation. Furthermore, tumorogenesis of several cancers types was also marked by specific methylation changes in their genomes. Therefore, it is useful to build a methylation profile to discover candidate genes, and to predict therapeutic outcomes [3], and patient survival in cancer.

Pancreatic carcinoma is the fourth most common cause of cancerrelated death in the United States, accounting for approximately 30,000 deaths annually, and death rates for it closely mirroring incidence rates [4]. Aggressive invasion and early metastasis are characteristic, such that $90 \%$ of patients have surgically unresectable disease at the time of diagnosis. Current chemotherapy regimens provide only palliation benefit.
Lack of early diagnostic biomarkers and ineffectiveness therapies for this cancer are among the major factors that contribute to its low survival rate [5]. The mechanism for the regulation of genes and the significance of alterations in DNA methylation status found in metastatic tumors, during pancreas carcinogenesis is not fully understood.

$S r c$ is the $M r 60,000$ non-receptor tyrosine kinase protein product of the proto-oncogene c-src. Src family nonreceptor protein tyrosine kinases transduce signals that control normal cellular processes such cell proliferation, adhesion and motility. Normally, cellular $s r c$ is held in an inactive state, but in several cancer types, abnormal events lead to elevated kinase activity of the protein, and cause pleiotropic cellular

*Corresponding authors: Padin-Iruegas ME, Department of Functional Biology and Health Sciences, Facultad de Fisioterapia, Campus a Xunqueira s/n 36005, Pontevedra- Spain, Tel:+ 34981 950887; Fax:+ 34981951 437; E-mail: mepadin@uvigo.es

Eugenyeva E, Medical Faculty, Pathology Department, Hospital Central Denia 03700, Partida Beniadlà, S/N. Dénia, Spain, E-mail: sersnada@yahoo.com

Received December 12, 2013; Accepted February 19, 2014; Published February 21,2014

Citation: Padin-Iruegas ME, Eugenyeva E, Herranz-Carnero M, Aguín Losada S, Brozos Vázquez E, et al. (2014) Demethylation with 5-Aza-2'-deoxycytidine Affects Oxidative Metabolism in Human and Mouse Non-small Cell Lung Cancer Cells. J Cancer Sci Ther 6: 045-051. doi:10.4172/1948-5956.1000247

Copyright: (c) 2014 Padin-Iruegas ME, et al. This is an open-access article distributed under the terms of the Creative Commons Attribution License, which permits unrestricted use, distribution, and reproduction in any medium, provided the original author and source are credited. 
Citation: Padin-Iruegas ME, Eugenyeva E, Herranz-Carnero M, Aguín Losada S, Brozos Vázquez E, et al. (2014) Demethylation with 5-Aza-2'deoxycytidine Affects Oxidative Metabolism in Human and Mouse Non-small Cell Lung Cancer Cells. J Cancer Sci Ther 6: 045-051. doi:10.4172/1948-5956.1000247

responses inducing transformation and metastasis. Ability of a cancer cell to undergo metastasis is to penetrate surrounding extracellular matrix; these processes are facilitated by the integrin family of cell adhesion molecules. Src signaling affects the formation of focal adhesions and the extracellular matrix, mainly due to interaction with integrins [6].

$c$-src in human cancer plays a critical role in the control cascade of cell growth. Accumulating evidence implicates $s r c$ as an important determinant of tumorogenesis, invasion, and metastasis. All these observations link src to multiple processes that determine the clinical outcome of a tumor, becoming a promising target for drug discovery and targeting. $S r c$ is overexpressed in over $70 \%$ of pancreatic carcinoma cell lines, and $s r c$ kinase activity is often increased. Overexpression of activated $c$-src has been reported to stimulate proliferation, cell migration and down-regulate E-cadherin expression in human pancreatic adenocarcinomas cell lines [7]. However, relatively little is known regarding the effects of $s r c$ and its partners on tumor development or chemoresistance.

In this study we analyzed epigenetic alterations in crucial pathways, mainly those derived from $S r c$, in order to demonstrate the important role of epigenetic control and $s r c$ pathway in pancreatic cancer development.

\section{Materials and Methods}

\section{Tumor samples}

Primary Pancreatic Ductal Adenocarcinoma (PDA) tumors were collected from Santiago de Compostela tumor bank. Inclusion criteria of newly diagnosed PDA cancer patients were based on the histopathologic information, covering from initial to advanced stages. An initial series of 61 paraffin-embedded pancreatic tumors, including a subset of paired normal tissue, were used to analyze methylation rates and evaluate the association of gene methylation with clinicopathologic variables. Demographic information is reflected on Table 1.

\section{DNA samples}

Genomic DNAs from paired normal and tumor pancreas samples were obtained from 61 patients. Genomic DNA from human amygdale was used as a control for unmethylated DNA, and the CpGenome Universal Methylated DNA (Chemicon), for methylated DNA. Genomic DNA was modified using EZ DNA Methylation Kit (Zymo Research) and by standard procedures of sodium bisulphite treatment according to [8]. DNA was purified using the Wizard DNA Clean-up system (Promega, Madison, WI), according to manufacturer's protocol.

\section{Distribution of aberrant promoter methylation}

Methylation-specific polymerase chain reaction (MSP) was carried out following the method developed by Herman et al. [8]. CpG islands were identified using the CpGPlot program (EMBOSS: http://bioweb. pasteur.fr/seqanal/interfaces/cpgplot.html)

Fragments of the human promoter of selected genes, containing the transcription start site, was selected from the National Centre for Biotechnology Information (NCBI) database. These sequences were analyzed with the CpGPlot software program (http://www.ebi. ac.uk/Tools/seqstats/emboss_cpgplot/) using the following settings: observed/expected CpG ratio of 0.6, minimum length island of $200 \mathrm{nt}$, and minimum $\mathrm{G}+\mathrm{C}$ content of $50 \%$.

MSP analysis was used to determine the methylation status in two

\begin{tabular}{|c|c|c|c|}
\hline Parameters & Value & $\mathbf{N}$ & $\%$ \\
\hline \multirow{2}{*}{ Gender } & $M$ & 36 & 59 \\
\hline & $\mathrm{F}$ & 25 & 41 \\
\hline \multirow[t]{2}{*}{ Tumor size } & $<2 \mathrm{~cm}$ & 9 & 14.8 \\
\hline & $>2 \mathrm{~cm}$ & 52 & 85.2 \\
\hline \multicolumn{4}{|l|}{ pTNM } \\
\hline \multirow[t]{3}{*}{ pT } & pT1 & 6 & 9.8 \\
\hline & pT2 & 7 & 11.5 \\
\hline & pT3 & 48 & 78.7 \\
\hline \multirow[t]{2}{*}{$\mathrm{pN}$} & pNO & 26 & 42.6 \\
\hline & $\mathrm{pN} 1$ & 35 & 57.4 \\
\hline \multirow[t]{2}{*}{ pM } & pM0 & 58 & 95.1 \\
\hline & $\mathrm{pM} 1$ & 3 & 4.9 \\
\hline \multirow[t]{5}{*}{ Clinical stage } & IA & 5 & 8.2 \\
\hline & IB & 1 & 1.6 \\
\hline & $I I A$ & 19 & 31.1 \\
\hline & IIB & 33 & 54.2 \\
\hline & IV & 3 & 4.9 \\
\hline \multirow[t]{3}{*}{$\begin{array}{l}\text { Resection } \\
\text { margins }\end{array}$} & Ro & 36 & 59 \\
\hline & $\mathrm{R} 1$ & 24 & 39.4 \\
\hline & $\mathrm{R} 2$ & 1 & 1.6 \\
\hline
\end{tabular}

Table 1: Clinicopathological characteristic of patients.

independent experiments for all samples: GSTP1, p16, RASFF1A, RARß2, CyclinD2, HIN-1, SOCS1, TIMP3, DAPK and TWIST1 genes, as previously described [9]. Primer sequences and PCR conditions are shown in Table 2. Bisulphite sequencing was performed in 5 samples for process control, as previously described [10]. Placental DNA treated in vitro with Sss I methyltransferase (New England BioLabs, Beverly, MA) was used as positive control for methylated alleles, and DNA from normal amygdale was used as negative control for methylated alleles. Controls without DNA were performed for each set of polymerase chain reaction.

PCR was performed in a Perkin Elmer 9600 DNA thermal cycler. Amplifications were carried out in a $25-\mu \mathrm{l}$ volume containing $200 \mu \mathrm{m}$ each of dATP, dCTP, dGTP, and dTTP; $0.2 \mu \mathrm{m}$ each of forward and reverse primers; $10 \mathrm{~mm}$ Tris ( $\mathrm{pH} 8.4$ ); $50 \mathrm{~mm} \mathrm{KCl} ; 1.5 \mathrm{~mm} \mathrm{MgCl}$; and 0.5 unit of Taq polymerase (Invitrogen). PCR products were separated in $8-12 \%$ nondenaturing acrylamide-Tris- $\mathrm{HCl}$ ( $\mathrm{pH}$ 8.8)-buffered gels or $2 \%$ agarose gels, silver stained or with ethidium bromide and visualized under UV illumination.

\section{Statistical analysis}

Hierarchical clustering was performed using Gene Cluster 3.0 and visualized using Treeview 3.0 (both from http://rana.lbl.gov/eisen) or PHYLIP: PHYLogeny Inference Package (http://evolution.genetics. washington.edu/phylip.html). Statistical analyses were performed by using SPSS (Version 10.1; SPSS, Chicago).

\section{Results}

\section{CpG island promoter methylation analysis of the investigated genes}

Clinico-pathological characteristics of the patients appear on Table 
Citation: Padin-Iruegas ME, Eugenyeva E, Herranz-Carnero M, Aguín Losada S, Brozos Vázquez E, et al. (2014) Demethylation with 5-Aza-2'deoxycytidine Affects Oxidative Metabolism in Human and Mouse Non-small Cell Lung Cancer Cells. J Cancer Sci Ther 6: 045-051. doi:10.4172/1948-5956.1000247

\begin{tabular}{|c|c|c|c|c|}
\hline \multirow{3}{*}{ GSTP1 } & \multicolumn{2}{|c|}{ Forward primer $5^{\prime}>3^{\prime}$} & \multirow{2}{*}{$\begin{array}{l}\text { Reverse primer } 5^{\prime}>\mathbf{3}^{\prime} \\
\text { GCCCAATACTAAATCACGACG }\end{array}$} & \multirow{3}{*}{$57^{\circ}$} \\
\hline & M & TTCGGGGTGTAGCGGCGTC & & \\
\hline & $U$ & GATGTTTGGGGTGTAGTGGTTGTT & ССАССССААТАСТАААТСАСААСА & \\
\hline \multirow{2}{*}{ P16 } & M & TTATTAGAGGGTGGGGCGGATCGC & GACCCCGAACCGCGACCGTAA & \multirow{2}{*}{$60^{\circ}$} \\
\hline & U & TTATTAGAGGGTGGGGTGGATTGT & САACCCCAAACCACAACCATAA & \\
\hline \multirow{2}{*}{ CyclinD2 } & M & GGCGGATTTTATCGTAGTCG & CTCCACGCTCGATCCTTCG & \multirow{2}{*}{$57^{\circ}$} \\
\hline & $U$ & AGAGTATGTGTTAGGGTTGATT & АСАТССТСАССААСССТССА & \\
\hline \multirow{2}{*}{ RAR 2} & M & GAACGCGAGCGATTCGAGT & GACCAATCCAACCGAAACG & \multirow{2}{*}{$55^{\circ}$} \\
\hline & $\mathrm{U}$ & GGATTGGGATGTTGAGAATGT & CAACCAATCCAACCAAAACAA & \\
\hline \multirow{2}{*}{ RASSF1A } & M & GTTGGTATTCGTTGGGCGC & GCACCACGTATACGTAACG & \multirow{2}{*}{$57^{\circ}$} \\
\hline & $\mathrm{U}$ & GGTTGTATTTGGTTGGAGTG & CTACAAACCTTTТАCACACAACA & \\
\hline \multirow{2}{*}{ HIN-1 } & M & GGTACGGGTTTTTTACGGTTCGTC & AACTTCTTATACCCGATCCTCG & \multirow{2}{*}{$57^{\circ}$} \\
\hline & $\mathrm{u}$ & GGTATGGGTTTTTTATGGTTTGTT & СААААСТТСТТАТАСССААТССТСА & \\
\hline \multirow{4}{*}{ socs1 } & M1 & GTT GTA GGA TGG GGT CGC GGT CGC & CTA CTA ACC AAA CTA AAA TCC ACA & \multirow{4}{*}{$63^{\circ}$} \\
\hline & U1 & GTT GTA GGA TGG GGT TGT GGT TGT & CTA CTA ACC AAA CTA AAA TCC ACA & \\
\hline & M2 & TTGTTCGGAGGTGGATTT & ACTAAAACGCTACGAAACCG & \\
\hline & U2 & TTTTTTCCTCTTCGTTTGGAGGTTGGATTTT & AAAACAAAACAATAAACTAAAACACTACAAAACCA & \\
\hline \multirow{2}{*}{ TWIST } & M & TTT CGG ATG GGG TTG TTA TC & AAA CGA CCT AAC CCG AAC G & \multirow{2}{*}{$56^{\circ}$} \\
\hline & u & TTT GGA TGG GGT TGT TAT TGT & CCT AAC CCA AAC AAC CAA CC & \\
\hline \multirow{2}{*}{ TIMP3 } & $M$ & CGTTTCGTTATTTTTTTGTTTTCGGTTTC & CCGAAAACCCCGCCTCG & \multirow{2}{*}{$59^{\circ}$} \\
\hline & $\mathrm{U}$ & TTTTGTTTTGTTATTTTTTGTTTTTGGTTTT & СССССАAАAАССССАССТСА & \\
\hline \multirow{2}{*}{ DAPK } & M & GGA TAG TCG GAT CGA GTT AAC GTC & CCC TCC CAA ACG CCG A & \multirow{2}{*}{$57^{\circ}$} \\
\hline & $\mathrm{U}$ & GGA GGA TAG TTG GAT TGA GTT AAT GTT & CAA АТС ССТ ССС АAA САС CAA & \\
\hline
\end{tabular}

Table 2: MSP-primers sequences for selected genes. M: Methylated; U: Unmethylated. Melting temperature are shown.

Methylation-specific PCR amplification of different genes promoter within the CpG island was performed on a set of paired normal and tumor pancreas samples.

We found a significant proportion of aberrant methylation in the promoter region of tumor suppressor genes selected: RAR $\beta 2$ (32.31\%), RASSF1A (56.92\%), GSTP1 (38.46\%), p16 (44.61\%), CyclinD2 (32.31\%), HIN-1 (44.61\%), DPK (23.5\%), TWIST1 (80\%), SOCS1 (98\%) and TIMP3 (83\%) Figure 1A. Illustrative examples of the MSP are shown in Figure 1B.

\section{Analysis of sequence-specific DNA methylation}

Methylation status of specific genomic DNA sequences was established by bisulphite genomic sequencing as previously described by Fraga et al. [10]. GSTP1, p16, RASFF1A, RAR $\beta 2$, CyclinD2 and HIN-1 were automatically sequenced to measure the methylation status of every single $\mathrm{CpG}$ dinucleotide for subsequent statistical analysis.

We performed high-resolution bisulphite genome sequencing of all $\mathrm{CpG}$ sites within the $\mathrm{CpG}$ island identified. Five PDA and control samples were selected for this assay, attending to the different intensities of PCR products in previous MSP amplifications. Tumor samples were highly methylated in most of the CpG sites examined (70-90\%). By contrast, their paired normal tissues were much less methylated (2040\%) Figure 1C.

\section{Promoter CpG island hypermethylation leads to gene inactivation}

CpG island promoter hypermethylation was found between $23 \%$ and $98 \%$ in PDA samples analyzed. All normal tissues analyzed, including lymphocytes and Amygdale, were mostly unmethylated.

Due to paraffin embedded tissue, the reliability of gene expression study with RT-PCR or Western blotting was reduce for the samples low quality; the only alternative was Immunohistochemistry (IHQ) not for its quantitative value, but for the possibility to results comparison. We found a nice correlation between IHQ values and methylation profile in all the samples analyzed; ie, 37\% of tumour samples has cyclin-D2 expression reduced by IHQ, similar to the percentage of cyclin-D2 methylation promoters samples (32.31\%) (data no shown).

\section{PDA methylation profiling}

DNA methylation levels were measured in 61 PDA and control samples. Only CpGs with a standard deviation across all samples and controls $>0.25$ were selected for an unsupervised hierarchical cluster analysis that segregated the PDA cohort into different main groups (Figure 2A). Clusters for clinicopathological characteristics and epigenetic profiles were obtained. Overlapping both clusters, results are grouped on seven discrete and homogeneous collections with shared characteristics (Figure 2B).

\section{Discussion}

Pancreatic cancer is one of the worse prognosis tumors. Difficult access for biopsy, clinical silencing until invasion of the bile duct and others factors means late diagnosis between 50,000 and 80,000 cases per year.

Numerous studies in PDA have not yet reached a level of medical management of this disease, leaving "shadows" in almost all levels of knowledge, control and monitoring of this type of cancer.

Accumulating evidence implicates $S r c$ as an important determinant of tumorogenesis, invasion, and metastasis in this pathology. These observations link Src to multiple processes that determine the clinical outcome of a tumor, make it a promising target for drug discovery. Src is overexpressed in over $70 \%$ of pancreatic carcinoma cell lines where $\mathrm{Src}$ kinase activity is often increased. Overexpression of activated $c$-Src has been reported to stimulate proliferation and migration and downregulate $E$-cadherin expression in human pancreatic adenocarcinomas cell lines [7]. There is clinical evidence that $S r c$ kinase expression plays a role in the development of chemoresistance, and its inhibition could enhance chemosensitivity of tumors [11]. Increased Src 
Citation: Padin-Iruegas ME, Eugenyeva E, Herranz-Carnero M, Aguín Losada S, Brozos Vázquez E, et al. (2014) Demethylation with 5-Aza-2'deoxycytidine Affects Oxidative Metabolism in Human and Mouse Non-small Cell Lung Cancer Cells. J Cancer Sci Ther 6: 045-051. doi:10.4172/1948-5956.1000247

A
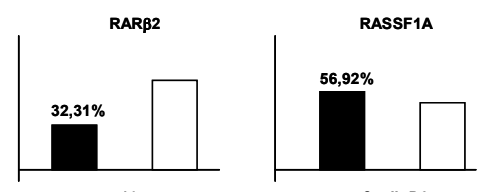

p16

CyclinD2
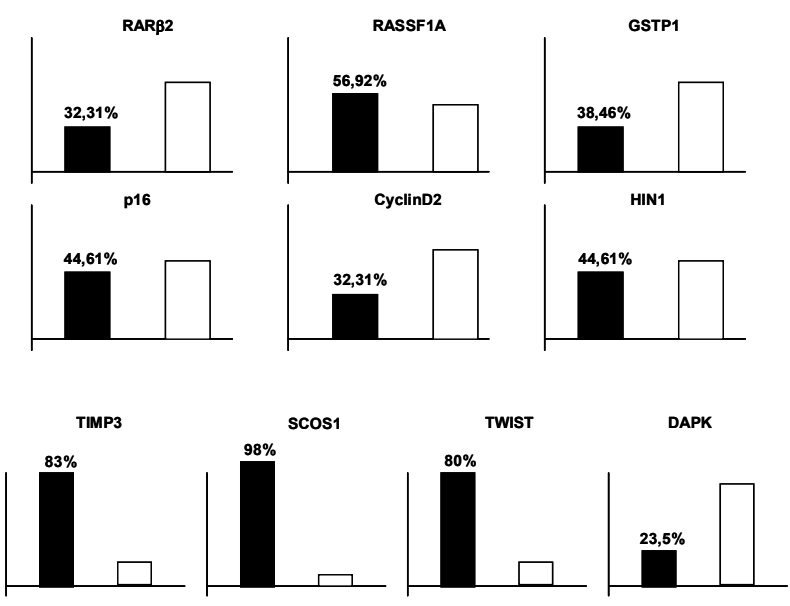

B

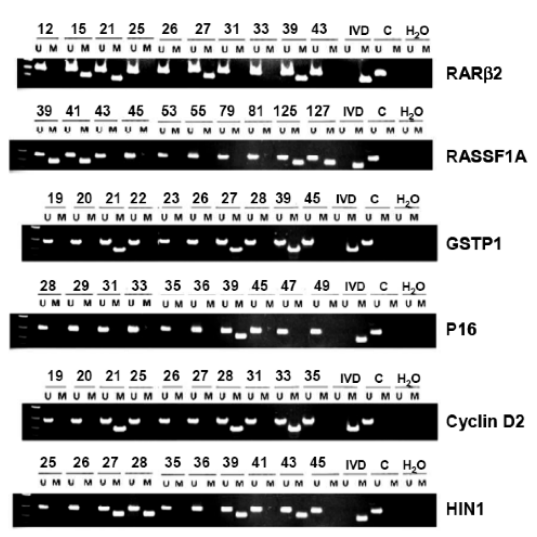

C

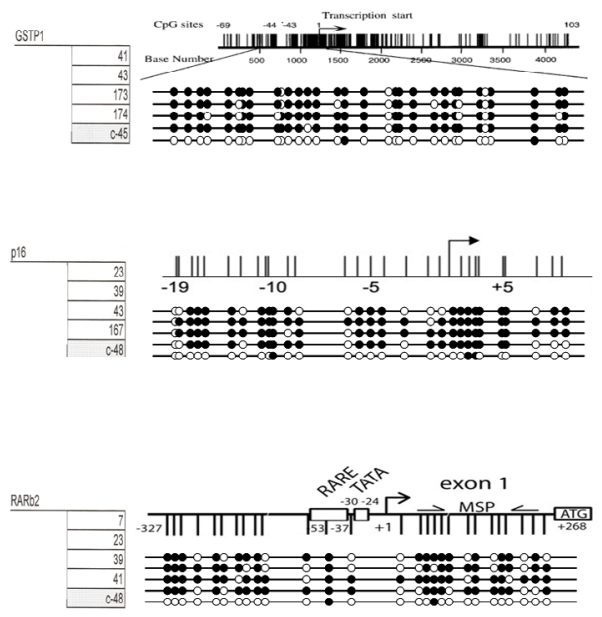

Figure 1: Methylation Specific PCR and Bisulfite Sequencing. (A) Graphic representation of Methylated/Unmethylated percentages for each of the studied genes: GSTP1, p16, RASFF1A, RARB2, CyclinD2, HIN-1, SOCS1, TIMP3, TWIST1 and DAPK. Black columns show Methylated percentage and white ones Unmethylated. (B) RARB2, RASFF1A, GSTP1, p16, CyclinD2, HIN-1 were hypermethylated in human primary PDA. Genomic DNA was isolated from a panel of 61 PDA and left untreated or treated with sodium bisulfite. MSP was performed using PCR primers specific for the unmethylated $(U)$ or methylated (M). A negative control for the methylated allele was done using DNA from normal human Amygdale (C). A negative control for the PCR reaction was performed in the absence of DNA ( $\mathrm{H}_{2} \mathrm{O}$ ). Placental DNA treated in vitro with Sss I methyltransferase (New England BioLabs, Beverly, MA) was used as positive control for methylated alleles (IVD). The nomenclature for each primary PDA is indicated at the top of the figure. (C) Bisulfite sequencing. Example of five PDA and one control samples in three genes (GSTP1, p16 and RARB2) are presented. Gene structure with transciption start site and CpG island position (vertical lines) are illustrated. CpG Methylation profiles: White circle: Unmethylated, Black circle: Methylated. 
Citation: Padin-Iruegas ME, Eugenyeva E, Herranz-Carnero M, Aguín Losada S, Brozos Vázquez E, et al. (2014) Demethylation with 5-Aza-2'deoxycytidine Affects Oxidative Metabolism in Human and Mouse Non-small Cell Lung Cancer Cells. J Cancer Sci Ther 6: 045-051. doi:10.4172/1948-5956.1000247

A
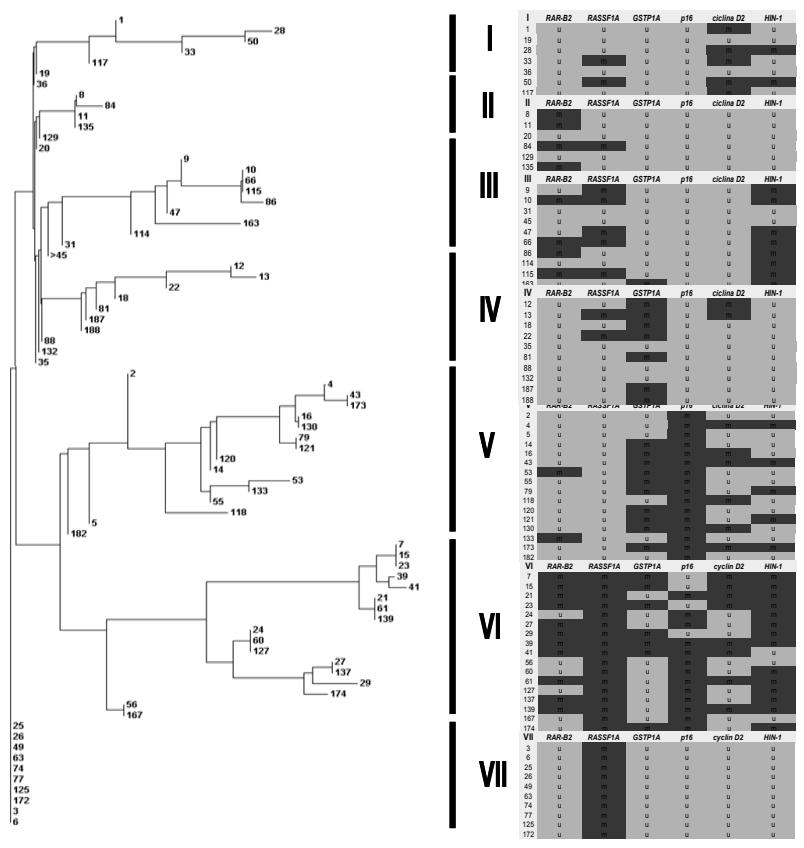

B
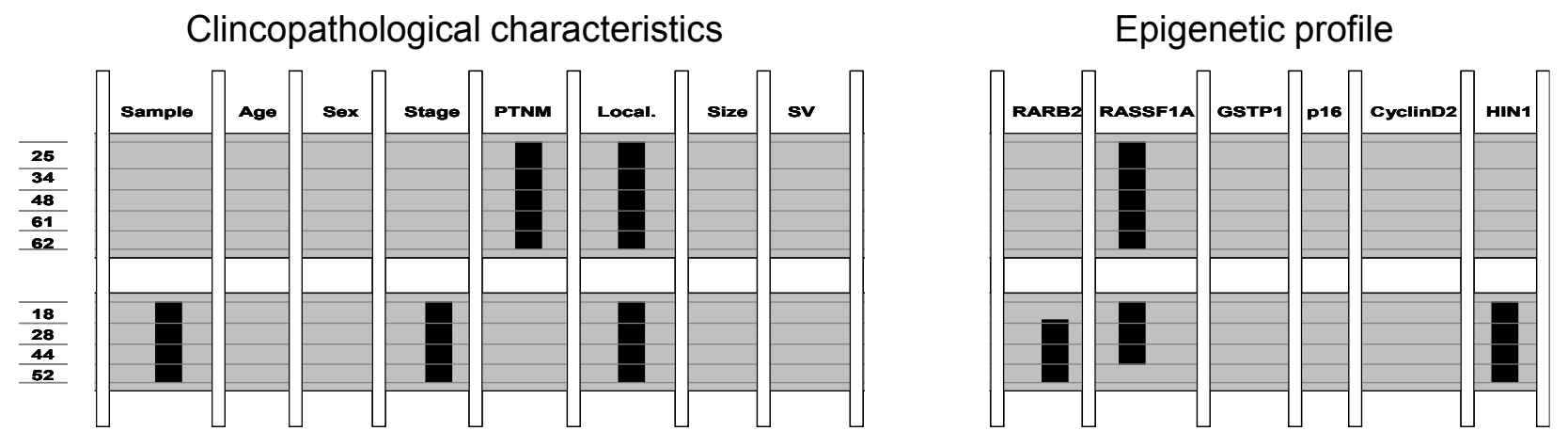

Figure 2: Cluster analysis. (A) Hierarchical clustering of DNA methylation profiles using PHYLogeny Inference Package (http://evolution.genetics.washington.edu/ phylip.html). (B) Cluster overlay diagram. Left panel clinicopathologycal characteristics: Sample, Age, Sex, Clinical Stage pTNM, Localization, Size and Survival. Rigth panel, epigenetic profiles of RARB2, RASSF1A, GSTP1, p16, Cyclin D2 and HIN-1 genes. Left numbers are PDA anonimized samples, and black blocks correspond to shared characteristics. Figure shows two matched groups (ie, upper lines tumors with the same pTNM and Localization are defined by just, and only, methylation in RASSF1A).

activity represents a cytoprotective mechanism capable of promoting chemoresistance.

Receptor signal transduction pathways are often compared to electrical circuitry networks, where the eventual outcome is dependent not only on the set of individual switches incorporated into the circuit board, but also on the combination of signals that are on or off at any one time. In this sense, SOCS-1 suppresses the JAK/STAT pathway by inhibiting JAK2 activity, and since STAT3 is downstream of JAK2 in the JAK/STAT pathway, SOCS-1 methylation status affect the level of phosphorylation of STAT3. pSTAT3 induction by $I L-6$ would be more likely to occur if SOCS-1 is methylated than if it is unmethylated. It was not observed induction of pSTAT 3 or JAK 2 by 5 -Aza-dC treatment despite induction of SOCS-1, but is suspected that the level of induction of SOCS-1 expression by 5 -Aza-dC was insufficient to result in a change in PSTAT3. There was not a clear relationship between $p S T A T 3$ levels and SOCS- 1 expression and this observation reflects the fact that STAT3 is regulated not only by JAK2 but also by other factors including the insulin-like growth factor-1 receptor $(I G F-R)$ and $\operatorname{Src}[12,13]$.

$S r c$ expression increases with disease progression, suggesting that Src may be more active in invasion and metastasis than in tumor formation [14].

Epigenetic phenomenon, by reversible, has become an interesting target for treatment. The 61 patients diagnosed with PDA, chosen for this study, represent a clinically uniform group with resectable pancreatic cancer at diagnosis. Our results agree with data regarding gender bias, classically indicating PDA prevalence in men over women by $40-50 \%[15]$.

We made a prospective study about the promoter methylation role in PDA. For this purpose we select genes involved in cell cycle (p16, 
Citation: Padin-Iruegas ME, Eugenyeva E, Herranz-Carnero M, Aguín Losada S, Brozos Vázquez E, et al. (2014) Demethylation with 5-Aza-2'deoxycytidine Affects Oxidative Metabolism in Human and Mouse Non-small Cell Lung Cancer Cells. J Cancer Sci Ther 6: 045-051. doi:10.4172/1948-5956.1000247

CyclinD2), DNA repair (GSTP1), proapoptosis..., etc. Due to previous studies describing methylation profile in cancer types, we select for our first approach the following genes: GSTP1, p16, RASFF1A, RARß2, CyclinD2 and HIN-1. Methylations percentages range between 32.3 and $56.9 \%$. Due to describe implication of Src pathway in pancreas tumors and although Src alterations in cancer always goes through overexpression, some relatives genes up- or downstream of this pathways could be involved. For this reason we select four genes involved in Src cascade: SOCS1, TIMP3, TWIST1 and DAPK. Methylation profiles of these genes goes from 23.5 to $98 \%$, clearly demonstrating implication of Src and epigenetic control in PDA.

We showed a clear prevalence of deregulation of one or more pathways in each of the seven clusters obtained grouping epigenetic profiles (Figure 2A). Group I emphasize the Cyclin D2 methylation prevalence; in group II RAR $\beta 2$ gene was silenced; in group III RAR $\beta 2$, RASSF1A, and HIN-1 genes are frequently methylated; in group IV GSTP1 gene is frequently methylated; the same join to hypermethylated p16 are found in group V. Special attention require group VI, the largest one $(n=16)$, with a high rate of aberrant methylation in almost all studied genes except GSTP1 and CyclinD2. Group VII presents aberrant methylation in $100 \%$ of cases for RASSF1A gene.

These findings, by itself, reflect the presence of epigenetic tumor subtypes with some "dominant" pathways down-regulated by promoter hypermethylation. The coexistence alterations of more than two pathways, typically divided by their targets and activation factors, such as RAR $\beta 2$, RASSF1A and HIN-1 (group III) and GSTP1 and p16 (group V), are consistent with the modern hypothesis of candidate or collaborative pathways that trigger a similar functional effect (ie, tumor progression) using different cell characteristics. The high percentage of aberrant methylation in multiple genes (group VI), suggest an accumulative effect, well known from animal models, in different pathways due to methylation. So we found groups that share clinical and pathological criteria with defined epigenetic alterations.

According with these findings, locally advanced tumors that are larger than $2 \mathrm{~cm}$ and extend through parapancreatic adipose tissue (without involvement of celiac axis or superior mesenteric artery) have a characteristic profile of epigenetic alterations in $R A S$ pathway, highlighting, once again, the involvement of this pathway as a crucial event in tumor progression of PDA (Figure 2B, upper group) .

Another group consists of 6 cases of primary tumors with clinical stage IIB [pT1, pT2 and pT3, with lymph node metastasis (pN1), but not remotely (M0)], which showed a combination of aberrant methylation of RAR 32 ( $4 / 6$ cases), RASSF1A (5/6 cases) and HIN-1 (6/6 cases). These finding evidence a nodal involvement in both primary tumors localized (pT1, pT2) and locally advanced (pT3), not dependent on tumor size.

A specific set of epigenetic alterations serves as a marker for tumor progression. The fact of the coexistence of different metabolic pathways involved in tumor progression corroborates the hypothesis of genetic and epigenetic changes collaborating in transition from a neoplasm to a metastatic disease.

As we describe above $S r c$ is frequently implicated in PDA. Some of our selected genes (GSTP1, p16, RASFF1A, RARß2, CyclinD2 and HIN-1) are related with Src pathway, through cell cycle (CyclinD2) or complex pathways interactions (Plag1/CNK1/RASSF1A/SRC) [16]. For this reason, we decided to go deeply in methylation study of control of $S r c$ pathway. We selected genes involved or related with $S r c$ pathway, already described in the literature as methylated-controled genes: SOCS1, competitive inhibition with Src protein for the receptor [17]; TWIST1, directly involve in $\operatorname{Src}$ control of Epithelial Mesenquimal Transition (EMT) and ductal carcinomas specificity, mainly through cadherins [18]; TIMP3 related with Src control of metastasis via matrix metalloproteases (MMPs) [19]; and DAPK, as key point in Src control of migration/invasion and apoptosis [20]. Epigenetic studies of new genes directly involved in Src pathway (SOCS1, TIMP3, TWIST1 and $D A P K$ ) results in a clear epigenetic expression control from 23.5 to $98 \%$ as mechanism implicated in development and progression of PDA.

In conclusion we demonstrated that epigenetic mechanism related with $\operatorname{Src}$ pathway could have implications in development of Pancreatic Ductal Adenocarcinomas.

\section{References}

1. Esteller M (2007) Epigenetic gene silencing in cancer: the DNA hypermethylome Hum Mol Genet 16 Spec No 1: R50-59.

2. Ryu B, Jones J, Blades NJ, Parmigiani G, Hollingsworth MA, et al. (2002) Relationships and differentially expressed genes among pancreatic cancers examined by large-scale serial analysis of gene expression. Cancer Research 62: 819-826.

3. Shen L, Waterland RA (2007) Methods of DNA methylation analysis. Curr Opin Clin Nutr Metab Care 10: 576-581.

4. Jemal A, Siegel R, Ward E, Hao Y, Xu J, et al. (2008) Cancer statistics, 2008 CA Cancer J Clin 58: 71-96.

5. Jimeno A, Hidalgo M (2006) Molecular biomarkers: their increasing role in the diagnosis, characterization, and therapy guidance in pancreatic cancer. Mol Cancer Ther 5: 787-796.

6. Duxbury MS, Ito H, Zinner MJ, Ashley SW, Whang EE (2004) Inhibition of SRC tyrosine kinase impairs inherent and acquired gemcitabine resistance in human pancreatic adenocarcinoma cells. Clin Cancer Res 10: 2307-2318.

7. Menke A, Philippi C, Vogelmann R, Seidel B, Lutz MP, et al. (2001) Downregulation of E-cadherin gene expression by collagen type I and type III in pancreatic cancer cell lines. Cancer Res 61: 3508-3517.

8. Herman JG, Baylin SB (2003) Gene silencing in cancer in association with promoter hypermethylation. N Engl J Med 349: 2042-2054.

9. San José-Enériz E, Agirre X, Román-Gómez J, Cordeu L, Garate L, et al (2006) Downregulation of DBC1 expression in acute lymphoblastic leukaemia is mediated by aberrant methylation of its promoter. $\mathrm{Br} \mathrm{J}$ Haematol 134: 137144

10. Fraga MF, Ballestar E, Paz MF, Ropero S, Setien F, et al. (2005) Epigenetic differences arise during the lifetime of monozygotic twins. Proc Natl Acad Sci U S A 102: 10604-10609.

11. Grant S, Dent P (2004) Kinase inhibitors and cytotoxic drug resistance. Clin Cancer Res 10: 2205-2207.

12. Fukushima N, Sato N, Sahin F, Su GH, Hruban RH, et al. (2003) Aberrant methylation of suppressor of cytokine signalling-1 (SOCS-1) gene in pancreatic ductal neoplasms. Br J Cancer 89: 338-343.

13. Sato N, Maitra A, Fukushima N, van Heek NT, Matsubayashi H, et al. (2003) Frequent hypomethylation of multiple genes overexpressed in pancreatic ductal adenocarcinoma. Cancer Res 63: 4158-4166.

14. Masaki T, Igarashi K, Tokuda M, Yukimasa S, Han F, et al. (2003) pp60c-src activation in lung adenocarcinomas. Eur J Cancer 39: 1447-1455.

15. Kelly KA, Bardeesy N, Anbazhagan R, Gurumurthy S, Berger J, et al. (2008) Targeted nanoparticles for imaging incipient pancreatic ductal adenocarcinoma. PLoS Med 5: e85.

16. Bhaskaran N, Souchelnytskyi S (2008) Systemic analysis of TGFbeta proteomics revealed involvement of Plag1/CNK1/RASSF1A/Src network in TGFbeta1-dependent activation of Erk1/2 and cell proliferation. Proteomics 8: 4507-4520.

17. Gingras S, Parganas E, de Pauw A, Ihle JN, Murray PJ (2004) Re-examination of the role of suppressor of cytokine signaling 1 (SOCS1) in the regulation of 
Citation: Padin-Iruegas ME, Eugenyeva E, Herranz-Carnero M, Aguín Losada S, Brozos Vázquez E, et al. (2014) Demethylation with 5-Aza-2'deoxycytidine Affects Oxidative Metabolism in Human and Mouse Non-small Cell Lung Cancer Cells. J Cancer Sci Ther 6: 045-051. doi:10.4172/1948-5956.1000247

toll-like receptor signaling. J Biol Chem 279: 54702-54707.

18. Lombaerts M, van Wezel T, Philippo K, Dierssen JW, Zimmerman RM, et al. (2006) E-cadherin transcriptional downregulation by promoter methylation but not mutation is related to epithelial-to-mesenchymal transition in breast cancer cell lines. Br J Cancer 94: 661-671.

19. Sounni NE, Roghi C, Chabottaux V, Janssen M, Munaut C, et al. (2004) Up- regulation of vascular endothelial growth factor-A by active membrane-type 1 matrix metalloproteinase through activation of Src-tyrosine kinases. J Bio Chem 279: 13564-13574.

20. Wang WJ, Kuo JC, Ku W, Lee YR, Lin FC, et al. (2007) The tumor suppressor DAPK is reciprocally regulated by tyrosine kinase Src and phosphatase LAR. Mol Cell 27: 701-716. 